\title{
Situational analysis of the subjective well-being of university software developers in Puebla
}

\author{
María del Carmen Cano-Alvarado르, Marco Tulio Cerón López², Juan Carlos \\ Pérez García ${ }^{1}$, Haydee Margarita Hernández Ruiz¹, Manuel González-Pérez ${ }^{1,3}$
}

${ }^{1}$ Universidad Popular Autónoma del Estado de Puebla A.C. (UPAEP). Centro Interdisciplinario De Posgrados (CIP). Posgrado en Planeación Estratégica y Dirección de Tecnología.

${ }^{2}$ Instituto de Estudios Universitarios (IEU Universidad)

${ }^{3}$ Sistema Nacional de Investigadores (nivel 1)

\begin{abstract}
Integral well-being is vital for the optimal functioning of people. The requirements for a software developer in the performance of their professional activity are varied and complex. These requirements range from working in multidisciplinary and multilingual teams, going through the challenge of technological advances of the discipline to commit to quality and innovation. To face these demands, it is essential that the developers have an optimal functioning, where the experience emotional and satisfaction with life play an important role. The objective of this article is to analyze the subjective well-being of university software developers in Puebla. The research is a quantitative cross-correlation study to identify statistically significant relationships between the different welfare variables. The study involved 47 university software developers from the city of Puebla. We use Pearson's multivariate correlation to validate the instruments and find relationships between variables, and Chi-squared statistics to calculate the dependency between them. The results reveal that the university software developers experience with higher incidence and intensity, the positive affections over the negatives. The affective balance (Net Affect), calculated as the difference of the weighted averages by duration between positive affective states and negative, was positive (mean $=1.31)$. "Concentrated" is the positive affective state with the highest incidence and with the highest reported intensity. "Tired" is the most experienced negative affect and highest in intensity. Developers spend $40 \%$ of their time experiencing negative affective states (U-index) and are moderately satisfied with their lives in general.
\end{abstract}

Keywords-Affective state, Net affect, Subjective wellbeing, U-index, University software developer.

\section{INTRODUCTION}

Integral well-being is vital for the optimal functioning of people. This optimal functioning should reflect total involvement in the activities aimed at achieving the objectives established by the person, both personal and professional objectives. The involvement in the activities depends among other aspects, of the motivations, affective states, capacities, achievements, desires, and aspirations that give meaning to the life of the people. Happiness is a final objective, something that people look for itself and not as a means to achieve something more (Rojas, 2014).

By its very nature, software development is a complex activity of absolute knowledge, which requires convergent and divergent thinking skills, as well as communication skills and effective interaction with others. These skills influence the process of abstracting real problems as well as the process of developing technological solutions that are creative and of quality. The process of developing software consists of a series of stages that involve tasks such as analyzing the requirements, designing the solution, implementing code and debugging, testing and maintaining the system. The challenges involved in each stage of development trigger a series of emotions and feelings that may favor or be detrimental to the performance, productivity or quality of the developer's work.

The literature on the subjective well-being of the person who creates the software is recent and scarce. Shaw (2004) highlighted the lack of research on emotions in Information Technology (IT) professionals. From five years ago, the research on the happiness of the developer has taken more interest. The studies have been in the line of the affective dimension of happiness, inquiring about the emotions that are triggered during the realization of software development activities and their relationship with productivity and performance, such as requirements engineering (Wrobel, 2013), coding and debugging the program (Khan, Brinkman \& Hierons, 2011; Graziotin, Wang \& Abrahamsson, 2013). Although the momentary emotions that the developer experiences during the software-building activities are a crucial aspect to their optimal performance, it might also be relevant to 
considerate aspects of vital satisfaction that prevail in the developer. This situation could be consuming the attention of the developer and influence their performance. The researchers of happiness have determined that the control of attention provide wellbeing (Csikszentmihalyi, 1997, 2012; Kahneman, 2006, 2012; Davidson, 2015).

The objective of our study is to analyze university software developer's subjective well-being of in Puebla. Consider both components of SWB, the affective wellbeing, and satisfaction with life; give us a better postcard of the happiness of the university software developer in Puebla. The questions that guide our work are; what is the well-being situation of university software developers in Puebla? What are the affections that most experience and with what intensity? What affective states bring greater well-being? How do developers use their time, with affection for pleasure or suffering? Are they satisfied with the life they have?

1.1 Measurement of Subjective Well-being

A happiness study approach that has been widely used by the scientific community is subjective well-being (SWB). Diener (2000) refers that SWB is both affect states and cognitive assessments that people make about their lives. These assessments include emotional reactions of pleasure or dislike about events, as well as judgments about their vital satisfaction. For the author, high subjective well-being happens when people predominantly experience pleasurable emotions over unpleasant and besides are satisfied with their lives.

Although there are several ways to measure the SWB, self-report measures have enjoyed the preference of the researchers. These measures are obtaining to ask directly to the respondent on their affective experience and satisfaction with life (Diener \& Ryan; Ryan, 2009; Rojas, 2014). An essential feature of measures affective states is the time in which they are collected: experienced online or in the retrospective (considering a time margin, for example, two or four weeks ago or the previous day). Measurements retrospectives can present biases of the memory while trying to remember how they experienced certain emotions in the past. Kahneman et al. (2006) argue that the measures of the SWB informed as close to the time of the experience are the more precise indicators of perceptions that people have about their experiences. In this idea, the most precise measurements of the SWB are those who are obtained utilizing Experience Sampling Method (ESM; Csikszentmihalyi and Larsen, 1987), in the what one the participant registers in real-time its emotions and feelings, thus avoiding the biases of the memory of the retrospective measures. One disadvantage of the ESM is that the continuous interference in the collection of affective experiences online can interrupt states of maximum concentration and absorption in the task, it which Csikszentmihalyi (1997) titled as "Flow."

A practical alternative to the ESM is the Day Reconstruction Method (DRM, Kahneman, Krueger, Schkade, Schwarz and Stone, 2004), based on diaries and time use. DRM incorporates procedures designed to reduce memory biases, the participants reconstruct its activities systematically and affect experiences of the previous day and provide additional information about how they spend its time (Kahneman et al., 2004; Kahneman, 2012). Thus, the DRM measures have advantages over the measures on-line ESM and on the retrospective measures: 1) are closer to the real experience because they are collected with a single day of difference, 2) the interruptions of the flow states are avoided and 3) They provide additional information on participants' time use. These features of DRM are favorable for our study, due to the different activities of a software developer, by themselves, are likely to generate constant flow states, whose effect will influence in the greater wellbeing of the developer.

\subsection{Previous studies}

Diverse are the benefits of the subjective well-being in domains like the health, the social relations and the work (in Deneve et al., 2012). In the domain of work, researchers have found that the welfare relates to the success in the race (Boehm \&amp; Lyubomirsky, 2008), the increase in productivity (Oswald et al., 2015 Zelenski et al. 2008) and the reduction in absenteeism (Peterson et al., 2011). So also can improve the creativity in the workplace (Amabile et al. 2005; Lyubomirsky et al. 2005; George and Zhou, 2007; Fredrickson, 2001) and the cooperation and collaboration during the negotiations (Lount, 2010). In a recent study, Deneve (2017) identified a series of essential characteristics of the work that favor the subjective well-being, such as the autonomy and the variety.

The research on the well-being of software developers is recent and limited. The studies have focused mainly on the dimension of emotional SWB. The exploratory work of Shaw (2004) put in evidence the lack of research on the emotions in the professionals of Information Technologies (IT).

So far this decade, there is a growing interest in studying the affective dimension of software developers, about productivity and performance at work. ColomoPalacios et al. (2010) found that emotions of high activation and low pleasure predict a high version of the requirements. Khan et al. (2011) report that affective states of high activation and valence have in the short term a positive effect on the performance of program purification. Wrobel (2013) found that "Frustrated" is the negative emotion most frequently reported by developers and that had the greatest negative impact on productivity, 
while the emotion "Angry" was the only negative emotion that had a positive effect in productivity. On the other hand, Enthusiastic was the positive emotion with greater frequency and with greater positive impact on productivity. Graziotin et al. $(2013,2014)$ found that there is a positive correlation between the valence and dominance dimensions of the emotions versus the selfevaluated productivity of the developers and that the happiest software developers had better performance in solving analytical problems. Ford \& Parnin (2015) found that $67 \%$ of the 45 participants in their study stated that "Frustrated" was a severe problem and that the causes were related among other factors, with the lack of a good mental model of the code, curves of learning of programming tools and failures in the estimation of effort. In a recent study of Graziotin et al. (2018), researchers identified a list of more than 200 factors that can cause the unhappiness of software developers when they develop software, which may influence their mental wellbeing, in the software development process and the artifacts produced. Among the factors identified are being stuck in the resolution of problems, the pressure of time and the poor quality of the code. The researchers claim for more research.

\subsection{Current Study}

The objective of our study is to analyze the subjective well-being of software developers in Puebla. The participants were 47 undergraduate students of Engineering in Information and Communication Technologies (ICT). They will be the future professionals in software development.

To measure the emotional well-being, we chose DRM. In this method, the participants must divide the previous day into episodes and register the activities carried out and how they felt. In following, record the start and end time of each episode, the place where they were, the people with whom they were, the level of challenge of the task and the ability required to carry it out. Subsequently to be asked to assess the intensity of the emotions that experienced during each episode, according to a structured list with 18 affective states. The selection of these affective states took as a basis the Russell's (2003) theory of affection Central, the affective states in the theory of the flow of Csikszentmihalyi (1997) and previous studies on affections in software developers (Wrobel, 2013; Kahn et al., 2011). Russell's theory frames emotions in two dimensions, one that goes from pleasure to dissatisfaction and another that goes from a high activation to deactivation. The eight affective states of the Csikszentmihalyi flow theory are activated when it combines the level of challenge with the skill required by the task, so that when the average level of challenge exceeds the skill, the person enters this state of optimal experience, generating a feeling of well-being
(Csikszentmihalyi 2012; Nakamura \& Csikszentmihalyi, 2014). About previous studies of affections in software developers, Wrobel (2013) and Ford \& Parnin (2015) found that respondents report to frustration as the negative affective state with the highest incidence. The measurement of emotions is by the level of intensity experienced, on a scale ranging from 0 to $10(0=$ not experienced, $10=$ maximu $\mathrm{m}$ intensity).

The list of the affective states selected for our study includes nine positive (concentrated, happy, optimistic, joyful, relaxed, control, competent, enthusiastic, creative) and nine negatives (worried, anxious, tense, frustrated, bored, apathetic, angry, sad, tired). It is of particular interest for our study the affective state "concentrated," this state implies staying focused on the current task while maintaining control of attention. Csikszentmihalyi (2003, 2012 pp. 103) defines the attention as "psychic energy, a faculty of the brain to process the information and to direct action," and adds that be aware of the present moment in the actual activity will provide moments of happiness. For Kahneman (2012), what we pay attention determines the emotional state, so that dominate the conscience, know how to control the attention and how to use the time produces experiences of wellbeing. We will discuss in more detail the analysis of affective state "Concentrated."

For the collection of data over the emotions experienced, we provide a booklet printed with a structured list of activities that a software developer university commonly performed, a list of places where the participant can develop activities and a list of persons with whom the participant interacts.

We intend with this study to bring new knowledge about the happiness of software developers. This effort adds to recent research aimed at exploring the human aspect of software engineering. However, we are interested, not only to increase productivity or performance at work but also for the developer to achieve optimal performance on a personal level. Aware that the architect of one's happiness is oneself, the developer must take an active part to maintain control over their attention and therefore spend their time in activities that provide greater well-being. The significant relationships arising between the emotional well-being and life satisfaction will allow us to develop proposals that promote the welfare of the university software developer.

The following sections describe the study methodology, results, discussion, and conclusions .

\section{METHOD}

\subsection{Participants}

The participants of this study are undergraduate students enrolled in advanced degrees in Engineering of Information and Communication Technologies (ICTS) of 
two institutions of higher level in Puebla. The participants, who are close to graduating, have already had the first contact with the labor sector in carrying out their professional practice according to the educational model of the institution. Before to the application of the survey, in every educational institution, the investigator gave a short session to sensitize the students on the relevancy of the study and its contribution to the body of knowledge of the software development. In addition, the investigator called the participants to provide truthful information to assure the validity of the results of the study. Finally, the researcher informed the students about the voluntary participation in the study and the guarantee of confidentiality of the data provided.

2.2 Measures

For our study, all instruments are subjected to scrutiny by the Pearson correlation coefficient to be validated or purged when the correlation throw values between 0.7 and 1.0. The criteria used to validate are: (a) accept or delete items repeated or duplicates, b) Remove items that the respondent would have confused as repeated, c) Delete or accept items introduced intentionally and (d) eliminate or accept items that relate randomly. The calculation of the internal consistency was through Cronbach Alpha.

Measures affective of DRM. The measures obtained with DRM are the Positive Affect, Negative Affect, Net Affect and the index of suffering U-index. The result of the scrutiny by the Pearson correlation coefficient for positive emotions resulted in a high correlation inter-item above 0.7 ; these results can be explained by the bias of further qualify high positive emotions versus negative emotions, according to Kahneman (2006). In the case of Negative Affect, the correlation considerable above the 0.7 between the affective status "pressed" versus "anxious," "concerned" and "frustrated" can be explained by the time of application of the survey, which was carried out during the period end-of-course. We remain with the affective states originally proposed, because each one of them is different in its conception according to their level of activation and including intentionally in our study. Both, affectivity positive $(\alpha=0.9640)$ and negative affectivity $(\alpha=0.9311)$ were internally consistent.

Satisfaction with Life Scale (SWLS, Diener, Emmons, Larsen and Griffin, 1985) in the Spanish version of Vázquez, Duque \& Herbás (2013). It is a self-reported measure of overall life satisfaction with five items measured on a 7-point Likert scale $(1=$ Completely disagree to $7=$ Strongly agree). The reliability of the study was acceptable above 0.756 .

The measure of satisfaction with academic performance is a single question on a scale of 1 to 7 ( $1=$ entirely unsatisfied to 7 = entirely satisfied).
Big Five Inventory-44: (BFI-44; Benet-Martinez and John, 1997), in the Spanish version. The BFI-44 scale is a Likert-type self-report measure of 5 points $(5=$ very according to 1 = strongly disagree) with 44 items that measure five major personality traits: Extraversion, Conscientiousness, Agreeableness, Neuroticism, and Openness. For our study, the inter-item validation employing the Pearson correlation did not present values higher than 0.7 . The reliability of the instrument was 0.7291 .

\subsection{Procedure}

In order to promote cognitive processes by remembering and grading the information requested, we apply the instruments on paper and pencil. The two sessions to collect the study information were in November 2017 and March 2018. Before to the application of the survey, the investigator gave a meeting of 10 minutes to sensitize the participants about the relevancy of the study for the discipline of engineering of software and of the importance of providing finished quality information, truthful and, to obtain consistent results with the reality.

The researcher briefed the participants on the confidentiality of their data for the exclusive use of the investigation and gave the filling instructions of each instrument in the package. All the instruments were applied in a single session directly at the facilities of each institution. We collect demographic information from participants on age, gender, marital status, and schooling, among others. The order of filling of the instruments was DRM, SWLS, and BFI. The average time of filling to the whole package was 90 minutes.

\section{RESULTS AND DISCUSSION}

3.1 Descriptive Analysis

Participants were 47 students of advanced degrees in Engineering in ICT's (age mean=23.4, SD= 3.18; 30\% women, $70 \%$ men) of two educational institutions in Puebla. The proportion of female students is the third party concerning men, which is characteristic of this type of university career. About the academic period studied, the average was $9.3(\mathrm{SD}=1.3)$. Concerning the labor situation, $53 \%$ reported having paid work and only $20 \%$ works on activities related to the software development process.

We collect 7,099 measurements on the intensity of emotional states, distributed in 704 episodes reported by participants (mean epis ode $=15.0, \mathrm{SD}=3.28$ ). The intensity of emotion is in a range of 0 to 10 , where $0=$ not experienced and 10=maximum intensity. The percentage of positive affects qualified with an intensity higher than 5 reached $71 \%$, while for the negative affects states the percentage was $56 \%$. The total time reported by the participants was of 754.95 hours. 
Tables 1 and 2 provide information on the incidence of the emotions experienced through reported episodes, in terms of frequency of occurrence, with intensity values above zero; the percentage that this represents of the total of positive experiences reported by the sample; and the average number of episodes in which the participants scored above zero for each the affective state. The range of reported episodes ranges from 0 to 20.

Table.1: Positive Affect experienced over day, DRM

\begin{tabular}{lccc}
\hline Affect & Frequency & $\begin{array}{c}\text { \% Positive } \\
\text { emotions } \\
\text { experienced }\end{array}$ & $\begin{array}{c}\text { Reported } \\
\text { episodes } \\
\text { (average) }\end{array}$ \\
\hline Concentrated & 486 & $6.9 \%$ & 10.34 \\
Happy & 484 & $6.9 \%$ & 10.30 \\
Optimistic & 460 & $6.6 \%$ & 9.79 \\
Joyful & 459 & $6.5 \%$ & 9.77 \\
Relaxed & 443 & $6.3 \%$ & 9.43 \\
Control & 438 & $6.2 \%$ & 9.32 \\
Competent & 433 & $6.2 \%$ & 9.21 \\
Enthusiastic & 411 & $5.9 \%$ & 8.74 \\
Creative & 347 & $4.9 \%$ & 7.38 \\
\hline
\end{tabular}

The affective states positive of highest incidence were concentrated and happy, and the lower incidence was creative. In the case of negative emotions of highest incidence were tired and anxious and the lower incidence was sad, as can be seen in Table 2 .

Table.2: Negative Affect experienced over day, DRM

\begin{tabular}{lccc}
\hline Affect & Frequency & $\begin{array}{c}\% \text { Negative } \\
\text { emotions } \\
\text { experienced }\end{array}$ & $\begin{array}{c}\text { Reported } \\
\text { episodes } \\
\text { (average) }\end{array}$ \\
\hline Tired & 431 & $6.1 \%$ & 9.17 \\
Anxious & 421 & $6.0 \%$ & 8.96 \\
Worried & 385 & $5.5 \%$ & 8.19 \\
Tense & 377 & $5.4 \%$ & 8.02 \\
Frustrated & 335 & $4.8 \%$ & 7.13 \\
Bored & 316 & $4.5 \%$ & 6.72 \\
Apathetic & 292 & $4.2 \%$ & 6.21 \\
Angry & 264 & $3.8 \%$ & 5.62 \\
Sad & 229 & $3.3 \%$ & 4.87 \\
\hline
\end{tabular}

Tables 3 and 4 show the mean and the standard deviation (SD) of positive and negative affective states. The averages correspond to the intensity of the reported emotions weighted by the duration of the episode, applied to the whole sample.

The shared information of tables 1 and 3 allows us to observe that the positive affect status "Concentrated" was the most frequent and evaluated with greater intensity by the participants, while "Creative" obtained the lowest average. These findings suggest that university software developers widely value the "concentrated" affective state, so we will analyze this situation in more detail to establish dependency relationships with other SWB variables. We will discuss this later in the article.

Table.3: Mean, Standard Deviation, Positive Affect

\begin{tabular}{lcl}
\hline \multicolumn{1}{c}{ Affect } & Mean & SD \\
\hline Concentrated & 5.1 & 3.0 \\
Optimistic & 4.7 & 3.4 \\
Competent & 4.5 & 3.4 \\
Happy & 4.5 & 2.9 \\
Control & 4.1 & 3.2 \\
Joyful & 4.1 & 3.1 \\
Enthusiastic & 3.8 & 2.8 \\
Relaxed & 3.8 & 2.6 \\
Creative & 3.3 & 2.9 \\
\hline
\end{tabular}

Table.4: Mean, Standard Deviation, Negative Affect

\begin{tabular}{lcc}
\hline Affect & Mean & SD \\
\hline Tired & 4.2 & 2.9 \\
Anxious & 3.8 & 2.6 \\
Tense & 3.5 & 2.5 \\
Worried & 3.4 & 2.5 \\
Frustrated & 3.1 & 2.5 \\
Bored & 2.4 & 2.0 \\
Apathetic & 2.3 & 2.3 \\
Angry & 2.0 & 2.1 \\
Sad & 1.6 & 1.9 \\
\hline
\end{tabular}

Table 4 presents descriptive statistics for negative affective states, where the highest mean corresponds to the Tired affective state, followed by Anxious; While Sad was evaluated lower.

Table 5 contains descriptive statistics for wellbeing. Affective measures of DRM suggest that participants score higher positive emotions than negative ones, resulting in the Net Affect in a positive balance. The Uindex measure indicates that the developers spend $40 \%$ of the time experienced displeasure emotions. About the overall satisfaction with life and the satisfaction in the domain of academic performance, developers said they feel moderately satisfied (the rating scale was $1=$ completely dissatisfied to $7=$ completely satisfied).

Table.5: Descriptive Statistics $S W B$

\begin{tabular}{lcc}
\hline Variable & Mean & $\begin{array}{c}\text { Standard } \\
\text { Deviation }\end{array}$ \\
\hline Positive Affect & 4.21 & 2.69 \\
Negative Affect & 2.90 & 1.92 \\
Net Affect & 1.31 & 2.43 \\
U-Index & 0.40 & 0.22 \\
Life Satisfaction & 5.39 & 1.44 \\
Academic Performance & 5.21 & 1.21 \\
\hline
\end{tabular}


The Positive Affect and the Negative Affect is the average of the weighted effect values of the sample. The mean and the standard deviation use these values for their calculation. For each participant, the weighted positive affect state is the sum of the scores of the positive emotions experienced multiplied by the duration of the episode in which they occurred. The weighted negative affect had the same treatment as the positive affect state, considering the negative emotions. The original score of the affect states was the intensity experienced, on a scale of 0 to 10 . The average values of positive and negative affects states tell us that participants rated the positive emotions higher than negative emotions. The DRM measure of Net Affect is the difference between "Positive Affect" minus "Negative Affect." The Net Affect calculated for the study indicates that the emotional balance of the software students, although minimal, is positive. Software developers are moderately happy.

The participant's U-index, which Kahneman et al. (2006) referred as the rate of misery, calculated as the proportion of the time reported by the participant in which stayed awake, experiencing predominantly negative emotions. The average of the U-index for the sample was 0.398; this means that almost 40 percent of the time developers experience negative emotions during the day. Concerning life satisfaction, less than half of the participants said they were "in agreement" or "very much in agreement" with the claims of the scale of Diener et al. (SWLS, 1985), which evaluates achievements and failures. Thus, $45 \%$ of the participants assessed the living conditions as excellent, and a $49 \%$ agree that if reborn would not change anything. On the other hand, for the affirmations about, if their life is close to the ideal (57\%) and to have achieved the things that are important (64\%), the percentages are above the average. Table 4 shows that the average value of the sample for the SWLS satisfaction scale was $5.39(\mathrm{SD}=1.44)$, which tells us that the undergraduate developers are moderately satisfied with their life. The degree of satisfaction with the academic performance evaluated by the participant consisted of a single item $(1=$ Not at all satisfied with $7=$ completely satisfied), and its average value 5.21 $(\mathrm{SD}=1.21)$ tells us that the developers are moderately satisfied with its academic performance.

Time Use

In Fig. 1 we provide information about the activities that consumed a higher amount of total time (754.95 hours) reported by the sample, as well as the proportion that each activity contributes to the U-index global, in which the participants experienced predominantly unpleasant emotions.

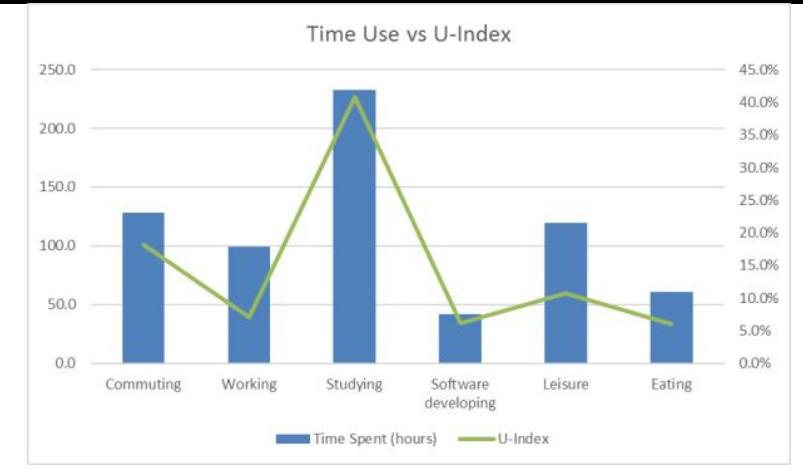

Fig 1. Time total spent in each activity vs proportion of U-Index total, which people reported to experience predominant negative emotions.

By the very nature of the sample, the global activity "studying" was the one that consumed more time of the participants, above the 230 hours (30.8\%). "Studying" encompasses activities like doing homework, attending classes and taking an exam. The "U-index" calculated for the activities represents $40.71 \%$ of the "U-index" of the study. The Commuting activity implies moving to the different places to realize activities. The displacement can be through different means, like traveling by car, by public transport or by walking. This activity also reports a high consumption in time use of 128 hours (17\%), as well as the preponderance of negative experiences of $18.1 \%$ that contributes to the global U-index. The Working activity reflects a lower time consumption of 98 hours (13.1\%) concerning total time, with a contribution of $7.1 \%$ to the global U-index. The "software developing" activity includes the life cycle activities of software development, requirements analysis, design, coding, testing, as well as the documentation and analysis of metrics. The time consumed in development activities reached 41.9 hours $(5.55 \%)$ of the total time with a $6.1 \%$ of contribution to the value of the U-index global. Finally, the activities carried out in the free time "Leisure," among which are resting, reading, watching TV, social networks or socializing, with 119.7 hours had the participation of $15.9 \%$ of total time reported by the sample, with a contribution of $10.8 \%$ to U-index of the overall sample. The participants spent 60 hours (8\%) of the total time to eat with a contribution of $2.4 \%$ to U-index global

The rest of the activities reported in the study (not shown in Figure 1) include personal grooming activities, household chores, exercising and meditating. Overall, these activities consumed 72.95 hours (10\%) of the total time sampled and contributed $11.2 \%$ of the U-index of the study. For the physical exercise activities, in total were 4.5 hours destined by the sample $(0.6 \%)$, with a contribution of $0.2 \%$ to the global U-index, while the time spent on activities of mental-spiritual types, such as meditating or praying, reached only 2.2 hours $(0.29 \%)$ of 
the total time, that represented $0.1 \%$ of the global Uindex.
The analysis correlational between the measurements of the well-being appears in Table 6 .

3.2 Correlation analysis

Table.6: Correlations Matrix, SWB

\begin{tabular}{lllllll}
\hline & 1 & 2 & 3 & 4 & 5 & 6 \\
\hline 1. Positive Affect & 1 & & & & & \\
2. Negative Affect & $0.49^{* *}$ & 1 & & & & \\
3. Net Affect & $0.72^{* *}$ & $-0.25^{*}$ & 1 & & & \\
4. U-Index & $-0.54^{* *}$ & 0.11 & $-0.68^{* *}$ & 1 & & \\
5. Life Satisfaction (SWLS) & 0.05 & $-0.47^{* *}$ & $0.42^{* *}$ & -0.23 & 1 & \\
6. Academic Performance & 0.03 & -0.21 & 0.20 & -0.13 & $0.44^{* *}$ & 1 \\
\hline
\end{tabular}

$* \mathrm{p}<.05, * * \mathrm{p}<.01$

The findings identified in correlational analysis for Net Affect, establish significant positive correlation $(r=0.725$, $\mathrm{p}<0.01)$ with positive affect, a significant negative relationship ( $r=-0249, p<0.05)$ with negative affect, and a positive correlation significant $(r=0.421, \mathrm{p}<0.01)$ with satisfaction with life (SWLS). For U-index the correlation is negative and significant with the positive affect ( $\mathrm{r}=-$ $0538, \mathrm{p}<0.01)$ and with Net Affect $(\mathrm{r}=-0684, \mathrm{p}<0.01)$. Satisfaction with life establishes a significant positive correlation $(r=0.438, p<0.01)$ with academic performance and a significant negative correlation $(r=-0475, \mathrm{p}<0.01)$ with negative affect.

3.3 Analysis of independence with Chi-square

Analysis of independence between the variables of the SWB

Table.7: Descriptive Statistics SWB

\begin{tabular}{|c|c|c|c|}
\hline $\begin{array}{l}\text { Variable } \\
\text { Independiente }\end{array}$ & $\begin{array}{c}\text { Variable } \\
\text { dependent }\end{array}$ & $\begin{array}{l}\text { Chi- } \\
\text { observed }\end{array}$ & $\begin{array}{l}\text { Chi- } \\
\text { critical }\end{array}$ \\
\hline & Negative & & \\
\hline Positive Affect & Affect & 17.936 & 3.841 \\
\hline Positive Affect & $\begin{array}{c}\text { Net Affect } \\
\text { Life }\end{array}$ & 24.177 & 3.841 \\
\hline Net Affect & Satisfaction & 5.226 & 3.841 \\
\hline Negative Affect & Net Affect & 5.226 & 3.841 \\
\hline Academic & Life & & \\
\hline Performance & Satisfaction & 6.300 & 3.841 \\
\hline
\end{tabular}

Result: Variables are dependents

Note: The calculation values for Chi-square is p-value $<0.05$, with a degree of freedom and a critical value of Chi-square $=3.841$

Table 7 is the summary of the multivariate analysis among the variables of the SWB to find possible dependencies using Chi-square. The findings of the analysis indicate that Net Affect has a dependency relationship with vital satisfaction (SWLS), with a calculated chi2 value of 5.2226 (chi-theoretical $=3.841$, p-value $<0.05$ and with a degree of freedom). It implies that developers who have an affect balance between positive and negative emotions are more satisfied with their lives in general. This result is in line with the results obtained in previous studies (Kahneman et al., 2004, 2006). Net Affect also has a strong relationship of statistical dependence with positive affection (Chi2 = 24.177, p-value < 0.05) and a moderate relationship with negative affection (Chi $2=5.226$, p-value $<0.05)$. The variables satisfaction with the life and the satisfaction with the academic performance also show statistical dependence $($ Chi2 $=6.3$, P-value $<0.05)$. The variables positive affect and negative affect present a statistically significant dependence (calculated Chi2 $=17.936$, chicritical $=3.841, \mathrm{p}$-value $<0.05$, a degree of freedom). Here it is worth noting that these variables were calculated as weighted averages for the duration of the episode for positive and negative affective states of the study, in addition to the fact that the application of the survey was carried out in a period of greater pressure for the participants.

With the affections weighted by the duration of the episode, we build contingency tables to test each statistical hypothesis between each pair of variables in the positive affect state and the affection net. Table 8 presents a summary of the analysis performed.

Table.8: Summary of the analysis of independence using Chi ${ }^{2}$ between the affective states positive and Net Affect

\begin{tabular}{lccc}
\hline $\begin{array}{l}\text { Variable } \\
\text { independent }\end{array}$ & $\begin{array}{c}\text { Net Affect } \\
\text { (AFNT) }\end{array}$ & $\begin{array}{c}\text { Chi } \\
\text { observed }\end{array}$ & Chi-critical \\
\hline Control & AFNT & 17.633 & 3.841 \\
Relaxed & AFNT & 15.630 & 3.841 \\
Concentrated & AFNT & 14.930 & 3.841 \\
Enthusiastic & AFNT & 7.567 & 3.841 \\
Happy & AFNT & 20.747 & 3.841 \\
Joyful & AFNT & 21.969 & 3.841 \\
Competent & AFNT & 14.930 & 3.841 \\
Creative & AFNT & 9.519 & 3.841 \\
Optimistic & AFNT & 29.227 & 3.841 \\
\hline
\end{tabular}

Result: Variables are dependents

Note: The calculation values for Chi-square is $\mathrm{p}$-value 
$<0.05$, with a degree of freedom and a critical value of

Chi-square $=3.841$

The literature on subjective well-being gives evidence that personality variables predict well-being. In our study we analyzed the relation of independence between the five personality traits BFI-44 and the variables of the subjective well-being, using Chi-square (chi-theoretical = 3.8414, p-value $<0.05$, with a degree of freedom). The results reveal dependency relationships between a) positive affect and the Extroversion trait with a calculated chi of 4.85 , b) Net affect vs. Extroversion with calculated Chi2 of 8,331), c) positive affect vs. openness with a calculated Chi value of 4.70 and d) Life satisfaction vs. Openness with calculated Chi value of 4.10. These findings allow us to observe that developers extroverted experience more positive affections and have a balance between positive affections and negative, while developers with the predominant feature "Openness" manifest higher levels in the dimension Positive Affect and evaluate a higher satisfaction with life.

3.4 Analysis of the independence of the affective state Concentrated

It is of great interest to our research to analyze the emotional state concentrated and its relationship on the other affective states. This emotional state represents one of the main features of the state of flow of the theory of Csikszentmihalyi (1997), the control of attention.

Table.9: Summary of test of independence with chisquare of the affective state Concentrated versus variables of the $S W B$

\begin{tabular}{|c|c|c|c|}
\hline $\begin{array}{l}\text { Variable } \\
\text { independent }\end{array}$ & $\begin{array}{c}\text { Variable } \\
\text { dependent }\end{array}$ & $\begin{array}{c}\text { chi } \\
\text { observed }\end{array}$ & chi critical \\
\hline \multirow{10}{*}{ Concentrated } & Control & 33.406 & 3.841 \\
\hline & Relaxed & 9.633 & 3.841 \\
\hline & Enthusiastic & 9.633 & 3.841 \\
\hline & Happy & 13.613 & 3.841 \\
\hline & Joyful & 13.290 & 3.841 \\
\hline & Competent & 32.307 & 3.841 \\
\hline & Creative & 16.027 & 3.841 \\
\hline & Optimistic & 21.195 & 3.841 \\
\hline & Positive Affect & 26.277 & 3.841 \\
\hline & Negative Affect & 17.895 & 3.841 \\
\hline
\end{tabular}

Result: Variables are dependent

Note: The calculation values for Chi-square is $p$-value $<0.05$, with a degree of freedom and a critical value of $\mathrm{Chi}^{2}=3.841$

Table 9 is a summary of the multivariate analysis using chi-squared between the affective state Concentrated and the positive affective variables of the study, analyzed of two in two. The result illustrates that the affect states variables with the highest level of dependency with the Concentrated state are Control (Chi2 $=33.4061$ ) and Competent (Chi2 = 32.3074), with a degree of freedom and a p-value of 0.05 . The above suggests that the software developer in the affect state "Concentrate" also experiences another positive affect such as feeling able, confident and having control. Staying focused or concentrate is having control over one's attention, over awareness itself, and according to Csikszentmihalyi (1997), this is the closest thing we are to feeling happy due we develop our potential. Similarly, for Kahneman (2015) the control of attention largely determines the emotional state and that the easiest way to increase the happiness is to control the use of time to do what you enjoy.

In addition to the above, the information shown in the Table 7 y 8 on the relationship of dependence between the affective state "Concentrated" versus "Positive Affect" (chi2=26.2778), and between "Concentrated" versus the "Net Affect" (chi2=14.9306), allow us to infer that Concentrated is an affect state that has a positive impact on the well-being of university software developers. However, not everything is honey on flakes. As shown in table 8, there is also a relationship of significant dependency between the affective state Concentrated with the global variable of Negative Affect (Chi2 = 17.8959, p-value $<0$ ), as well as other negative affective states. From our findings on the dependency ratio between concentrated and negative affective states like, worried $($ Chi $2=13.6130$, p-value $<0.05)$, frustrated $($ Chi $2=$ 10.0494, p-value < 0.05), Anxious (Chi2 = 14.1476, pvalue $<0.05)$ and Tense (Chi2 $=16.1269$, P-value < 0.05), we can infer that the effort to control the attention has a high cost for the developers. While staying focused produces a sense of wellbeing when performing the task, also have to deal with the non-pleasurable emotions that can arise. Various proposals for the control of attention, and with it the control of the emotions, have emerged in recent years. However, selecting, adopting or developing an appropriate proposal to the profile of each person, and in the particular case for the profile of the university software developer for promoting greater well-being and optimum performance, is a reason for greater research.

\section{CONCLUSION}

1. Developers experience with higher frequency and intensity positive affections that negative

2. The positive affect states presented a high positive interrelation inter-item, on the other hand, the interrelation inter-item between the negative emotions also turned out to be positive but less significant.

3. The index of suffering or U-index of the sample indicates that software developers spend $40 \%$ of their time experiencing mostly intense negative emotions over 
positive emotions.

4. University developers spend almost a third part of the day in academic activities (30\%), $17 \%$ in commuting and the $15.9 \%$ in leisure activities $15.9 \%$. The suffering U-index of these three activities amounts $68 \%$ of study total U-index. It is possible to assume that the establishment of support programs to promote the optimal functioning integral of the developers will help reduce the U-index and improve the emotional well-being. Minimize the percentage of suffering index can influence a better performance of the developers on a personal and professional level.

5. The most frequently experienced positive affect was Concentrated while Creative was the least frequent. On the other hand, Tired was the negative affect state most experienced by the participants and Sad the least experienced.

6. The Net Affect has a dependent relationship with satisfaction with life (SWLS).

7. Only $55 \%$ of participants are satis fied with life, $45 \%$ say that the conditions of their lives are excellent, $57 \%$ that their life is close to their ideal, $64 \%$ were satisfied with their achievements and $49 \%$ that, if reborn, would not change anything of their life. The average satisfaction with life for the entire sample was 5.39, on a scale from 1 to 7. Developers are moderately satisfied with their lives. The satisfaction with the academic performance shows no correlation with the variables DRM of affection, but if it shows significant positive correlation with satisfaction with life in general (SWLS).

8. University developers with dominant characteristics of the BFI-extroversion dimension experience more emotions that are positive and have better affect balance. On the other hand, those who are more open to new experiences, who have dominant characteristics of BFIopenness, experience more emotions that are positive and are more satisfied with life (SWLS).

9. The life of the University software developers presents a lot of challenges and pressures, where time plays a critical role. Use the limited resource time to engage fully in the relevant activities and thus keep the attention, can lead to being more productive, more creative and happier. An expanded study on the satisfaction in different domains of life and other dimensions of being, such as social, health, spiritual and psychological, will paint a more detailed postcard on the integral well-being and optimal functioning of the developers of software in the field personal and professional.

10. The welfare approach staff in the field of ICT could serve, mainly so that the university developer aware that their emotional well-being and satisfaction vital depend primarily on him and must act consistently to achieve its ideal functioning. Second, educational institutions and software organizations could establish guidelines and programs that foster greater well-being and thus influence the integral functioning of the developers.

11. The results give us a guide to continue research on the integral well-being of software developers and its impact on productivity, performance creative, commitment to the improvement and quality in the process of software development, among others.

12. Generate a profile of personal well-being for the software developer university will allow, at the level of the individual, to educational level and in the sand organizational, promote actions to foster the wellbeing in the areas of opportunity of the developer. It will lower developer's DRM U-index from before they get into at the professional field.

\section{REFERENCES}

[1] Amabile, T. M., Barsade, S. G., Mueller, J. S., \& Staw, B. M. (2005). Affect and creativity at work. Adminis trative science quarterly, 50(3), 367-403.

[2] Benet-Martínez, V., y John, O.P. (1997).The Big Five across cultures and ethnic groups: Multitrait multimethod analyses of the big five in Spanish and English. Journal of Personality and Social Psychology, 75(3), 729-750.

[3] Boehm, J. K., \& Lyubomirsky, S. (2008). Does happiness promote career success?. Journal of career assessment, 16(1), 101-116.

[4] Colomo-Palacios, R., Hernández-López, A., GarcíaCrespo, Á., \& Soto-Acosta, P. (2010). A study of emotions in requirements engineering. In Organizational, Business, and Technological Aspects of the Knowledge Society (pp. 1-7). Springer Berlin Heidelberg.

[5] Csikszentmihalyi, M, \& Larson, R. (1987). Validity and reliability of the experience sampling method. Journal of Nervous and Mental Disease, 175, 526536.

[6] Csikszentmihalyi, M. (2012). Fluir en los negocios: una psicología de la felicidad. Editorial Kairós.

[7] Csikszentmihalyi, M. (2012). Fluir: una psicología de la felicidad. Editorial Kairós.

[8] Davidson, R. J., \& Schuyler, B. S. (2015). Neuroscience of happiness. World happiness report, 88-105.

[9] De Neve, J. E., Diener, E., Tay, L., \& Xuereb, C. (2013). The Objective Benefits of Subjective WellBeing. In Helliwell, J., Layard, R., \& Sachs, J., eds. World Happiness Report 2013. Social Science Research Network.

[10] De Neve, J. E. \& Ward, G. (2017). Happiness at Work. In: John Helliwell, Richard Layard \& Jeffrey 
Sachs (Ed.) World Happiness Report 2017. Chapter 6, p. 144-177, Sustainable Development Solutions Network, New York.

[11] Diener, E. D., Emmons, R. A., Larsen, R. J., \& Griffin, S. (1985). The satisfaction with life scale. Journal of personality assessment, 49(1), 71-75.

[12] Diener, E. (2000). Subjective well-being: The science of happiness and a proposal for a national index. American psychologist, 55(1), 34

[13] Diener, E., \& Ryan, K. (2009). Subjective wellbeing: A general overview. South African Journal of Psychology, 39(4), 391-406.

[14] Fredrickson, B. L. (2001). The role of positive emotions in positive psychology: The broaden-andbuild theory of positive emotions. American Psychologist, 56(3), 218-226.

[15] Ford, D., \& Parnin, C. (2015, May). Exploring causes of frustration for software developers. In Proceedings of the Eighth International Workshop on Cooperative and Human Aspects of Software Engineering (pp. 115-116). IEEE Press.

[16] George, J. M., \& Zhou, J. (2007). Dual tuning in a supportive context: Joint contributions of positive mood, negative mood, and supervisory behaviors to employee creativity. Academy of Management Journal, 50(3), 605-622.

[17] Graziotin D, Wang X, Abrahamsson P. (2014), Happy software developers solve problems better: psychological measurements in empirical software $\begin{array}{lll}\text { engineering. } & \text { PeerJ } & \text { 2:289 }\end{array}$ https://doi.org/10.7717/peeri.289

[18] Graziotin, D., Wang, X., \& Abrahamsson, P. (2013, June). Are happy developers more productive?, In International Conference on Product Focused Software Process Improvement (pp. 50-64). Springer, Berlin, Heidelberg.

[19] Graziotin, D., Fagerholm, F., Wang, X., \& Abrahamsson, P. (2018). What happens when software developers are (un)happy. Journal of Systems and Software, 140, 32-47.

[20] Kahneman, D., Krueger, A. B., Schkade, D. A., Schwarz, N., \& Stone, A. A. (2004). A survey method for characterizing daily life experience: The day reconstruction method. Science, 306(5702), 1776-1780.

[21] Kahneman, D., \& Krueger, A. B. (2006). Developments in the measurement of subjective well-being. Journal of Economic perspectives, 20(1), 3-24.

[22] Kahneman, D. (2012). Pensar rápido, pensar despacio (Trad. J.Chamorro). México: Debate. (Trabajo original publicado en 2011).
[23] Khan, I.A., Brinkman, W.-P. , Hierons, R.M., (2011). Do moods affect programmers' debug performance? Cogniti. Technol. Work 13 (4), 245258.

[24] Lount, J. R. B. (2010). The impact of positive mood on trust in interpersonal and intergroup interactions. Journal of Personality and Social Psychology, 98, $420-433$

[25] Lyubomirsky, S., King, L., \& Diener, E. (2005). The benefits of frequent positive affect: Does happiness lead to success? Psychological Bulletin, 131(6), 803-855. doi:10.1037/0033-2909.131.6.803

[26] Nakamura, J., \& Csikszentmihalyi, M. (2014). The concept of flow. In Flow and the foundations of positive psychology (pp. 239-263). Springer Netherlands.

[27] Oswald, A. J., Proto, E., \& Sgroi, D. (2015). Happiness and productivity. Journal of Labor Economics, 33(4), 789-822.

[28] Peterson, S. J., Luthans, F., Avolio, B. J., Walumbwa, F. O., \& Zhang, Z. (2011). Psychological capital and employee performance: A latent growth modeling approach. Personnel Psychology, 64(2), 427-450.

[29] Rojas, M. (2014). El Estudio Científico de la Felicidad. México: Fondo de Cultura Económica.

[30] Russell, J. A. (2003). Core affect and the psychological construction of emotion. Psychological review, 110(1), 145.

[31] Shaw T. The emotions of systems developers. Proceedings of the 2004 conference on Computer personnel research Careers, culture, and ethics in a networked environment - SIGMIS CPR '04 2004; 124. DOI: $10.1145 / 982372.982403$.

[32] Vázquez, C., Duque, A., \& Hervás, G. (2013). Escala de Satisfacción con la Vida (SWLS) en una muestra representativa de adultos españoles: validación y datos normativos. Spanish Journal of Psychology, 16, E82.

[33] Wrobel, M. R. (2013, June). Emotions in the software development process. In Human System Interaction (HSI), 2013 The 6th International Conference on (pp. 518-523). IEEE.

[34] Zelenski, J. M., Murphy, S. A., \& Jenkins, D. A. (2008). The happy-productive worker thesis revisited. Journal of Happiness Studies, 9(4), 521537. 